\title{
Excystment of Axenically Prepared Cysts of Hartmannella culbertsoni
}

\author{
By D. C. KAUSHAL AND O. P. SHUKLA \\ Division of Biochemistry, Central Drug Research Institute, Lucknow, India
}

(Received I5 July 1976; revised I September 1976)

\begin{abstract}
SUMMARY
Axenically prepared cysts of Hartmannella culbertsoni readily excysted in the presence of heat stable factors prepared from Escherichia coli, Klebsiella aerogenes, Staphylococcus aureus, Sarcina lutea, Bacillus subtilis, Bacillus megaterium and several fungi. Peptone, proteose peptone, tryptone or amino acids also promoted excystment. Crowding of the cysts and dilution of bacterial extracts adversely affected the excystment. Continual presence of the factors in the medium was essential for excystment.
\end{abstract}

\section{INTRODUCTION}

Many different environmental factors can trigger the excystment of amoebae (Singh, 1973). The presence of bacteria appears to be essential for the process (Beers, 1946; Crump, 1950; Hall, 1953) and the bacterial strains that permit excystment show a certain degree of selectivity (Dudziak, 1955; Singh, Das \& Saxena, 1963). Following the suggestion of Crump (1950) that the above triggering action may be associated with some metabolic products of bacteria, Singh, Mathew \& Anand (1958) and Singh, Mathew \& Sreenivasaya (I956) prepared a heat-labile, dialysable factor from a Klebsiella (Aerobacter) sp. and a heat-stable, water-soluble factor from the same organism and also Escherichia coli. Part of the excystment-promoting activity was due to amino acids present in these extracts, and indeed exogenously added amino acids did promote the excystment of amoebic cysts (Drozanski, 196I ; Jeffries, I962; Singh, Datta \& Dutta, I97I ; Singh, Saxena \& Iyer, 1965).

Most previous studies used cysts prepared in the presence of either monobacterial or mixed cultures after the cysts had been exposed to $\mathrm{HCl}$, trypsin or detergents to remove bacteria (Singh et al., 1965, 1971). Cysts exposed to $\mathrm{HCl}$, detergents or enzymes probably retain their viability but change their permeability (Imam, Dutta \& Agarwala, I968). The question as to how far these changes affect subsequent excystment has not been unequivocally answered.

Hartmannella culbertsoni can grow in a medium without bacteria and the resulting trophozoites can be transformed into mature viable cysts in a liquid medium containing $\mathrm{NaCl}, \mathrm{MgCl}_{2}$ and taurine (Kaushal \& Shukla, I975). Such cysts do not require any pretreatment since they are not contaminated with live or dead bacteria and hence provide an ideal starting material for studying the biochemistry of excystment. This paper describes some studies on the excystation of cysts formed from axenically grown $H$. culbertsoni induced by cell-free extracts of a few bacteria, fungi, growth media and amino acids. 


\section{METHODS}

Growth and harvesting of cells. Hartmannella culbertsoni (Culbertson strain A-I; Singh \& Das, 1970) was obtained from Dr. B. N. Singh of this Institute and grown axenically in medium containing: peptone $(2 \%, \mathrm{w} / \mathrm{v}) ; \mathrm{NaCl}(0.5 \%, \mathrm{w} / \mathrm{v})$; thiamin, Io $\mathrm{mg}^{-1}$; and cyanocobalamin, $5 \mu \mathrm{g} \mathrm{1}^{-1}$ - as described earlier (Kaushal \& Shukla, 1975).

Encystment. Encystment was induced in a liquid medium containing $15 \mathrm{mM}^{-\mathrm{MgCl}_{2}}$, $20 \mathrm{~mm}$-taurine and $86 \mathrm{~mm}-\mathrm{NaCl}$. The above medium $(300 \mathrm{ml})$ was dispensed into I 1 Erlenmyer flasks, sterilized and inoculated with freshly harvested amoebae (Io $\mathrm{ml} ; 3 \times 10^{8}$ cells) and incubated with shaking at $28 \pm 2{ }^{\circ} \mathrm{C}$. Transformation of trophozoites into cysts was observed microscopically as described previously (Kaushal \& Shukla, 1975). After 4 to 5 days, the cysts were collected, kept at $4{ }^{\circ} \mathrm{C}$ for 2 days and then washed several times by dispersing in sterile $150 \mathrm{~mm}-\mathrm{NaCl}$, centrifuging at $500 \mathrm{~g}$ for $3 \mathrm{~min}$ and finally suspending in I $50 \mathrm{~mm}-\mathrm{NaCl}$. When stored at $4{ }^{\circ} \mathrm{C}$, no adverse effect was noticed on excystment for up to one month of storage.

Preparation of bacterial and fungal extracts. Escherichia coli, Klebsiella (Aerobacter) aerogenes, Staphylococcus aureus, Sarcina lutea, Bacillus subtilis and Bacillus megaterium were grown in nutrient broth, harvested by centrifuging and an extract prepared by the method of Singh, Mathew \& Anand (1958). The aqueous extract of bacteria containing the heat-stable, water-soluble components was freeze dried, and reconstituted in $0.5 \% \mathrm{NaCl}$ to yield a $\mathrm{I} \%$ solution (I0 $\mathrm{mg} \mathrm{ml}^{-1}$ ) of excystment factor(s). Aspergillus niger, Chaetomium globosum, Myrothecium verrucaria, Trichoderma viride and an unidentified isolate $\mathrm{F}_{1}$ were grown in a medium at $\mathrm{pH} 5.0$ containing $\left(\mathrm{gl}^{-1}\right)$ : glucose, IO; peptone, $5 ; \mathrm{KH}_{2} \mathrm{PO}_{4}$, I ; and $\mathrm{MgSO}_{4} \cdot{ }_{7} \mathrm{H}_{2} \mathrm{O}, 0.5$. Fungal extracts were prepared by the method of Jehan et al. (I975).

Excystment procedure. Excystment was carried out in tubes $(25 \times 150 \mathrm{~mm})$ containing $4.5 \mathrm{ml}$ of sterile $\mathrm{NaCl}(0.5 \%)$, the indicated amount of the agents under test and $0.5 \mathrm{ml}$ cyst suspension $\left(5 \times 10^{5}\right.$ cysts $\left.\mathrm{ml}^{-1}\right)$. The tubes were shaken at $35 \pm 2{ }^{\circ} \mathrm{C}$. The hatching of double walled cysts of Hartmannella culbertsoni took place in two stages. First the amoebae shrank and moved within their cyst wall (intermediate form). Excystment was complete when the trophozoite came through an opening in this wall. At this stage the cyst wall or the empty cyst was still visible. Samples were taken aseptically at intervals and counts were made of all forms using a haemocytometer. Samples were taken at the end of the experiment and inoculated into nutrient broth to check for possible bacterial growth though in no case was there any contamination.

\section{RESULTS}

Excystment of $H$. culbertsoni in growth medium and in the presence of an E. coli extract

Excystment of $H$. culbertsoni occurred in the presence of an extract of $E$. coli to the same extent as it did in a liquid growth medium (Table I). During excystment the number of amoebae (cysts plus intermediate forms plus trophozoites) did not increase either in the $E$. coli extract or in the growth medium. E. coli extract does not support the growth of amoebae (Singh et al., 1958) up to $72 \mathrm{~h}$. In medium containing $E$. coli extract, the number of cysts emerging at $48 \mathrm{~h}$ was more but the total number of amoebae remained the same. The number of empty cysts, however, was obviously not identical with the number of trophozoites due to degradation of empty cysts presumably by enzymes secreted by the amoebae (Kaushal \& Shukla, 1976). In growth medium, however, the number of trophozoites increased as a result of not only more cysts hatching but also due to multiplication of the 
Table I. Excystment in growth medium and E. coli extract

\begin{tabular}{|c|c|c|c|c|c|c|c|c|}
\hline \multirow[b]{2}{*}{ Time(h) } & \multicolumn{4}{|c|}{$\mathrm{IO}^{-3} \times \mathrm{No} . \mathrm{ml}^{-1}$ in growth medium* } & \multicolumn{4}{|c|}{${ }_{10^{-3}} \times$ No. $\mathrm{ml}^{-1}$ in E. coli extract $\left(10 \mathrm{mg} \mathrm{ml}^{-1}\right)$} \\
\hline & Cysts & $\begin{array}{l}\text { Intermed- } \\
\text { iate forms }\end{array}$ & $\begin{array}{l}\text { Tropho- } \\
\text { zoites }\end{array}$ & $\begin{array}{c}\text { Empty } \\
\text { cysts }\end{array}$ & Cysts & $\begin{array}{l}\text { Intermed- } \\
\text { iate forms }\end{array}$ & $\begin{array}{c}\text { Tropho- } \\
\text { zoites }\end{array}$ & $\begin{array}{c}\text { Empty } \\
\text { cysts }\end{array}$ \\
\hline 0 & 500 & 一 & - & - & 500 & - & - & - \\
\hline 24 & $110 \pm 27$ & $60 \pm 13$ & $330 \pm 39$ & $330 \pm 35$ & $60 \pm 16$ & $110 \pm 23$ & $330 \pm 40$ & $330 \pm 52$ \\
\hline 48 & $80 \pm 20$ & $30 \pm 10$ & $450 \pm 34$ & $290 \pm 34$ & $40 \pm 10$ & $40 \pm 8$ & $420 \pm 47$ & $350 \pm 33$ \\
\hline
\end{tabular}

Table 2. Excystment with different concentrations of cysts

The excystment medium was $E$. coli extract $\left(\mathrm{I} 0 \mathrm{mg} \mathrm{ml}^{-1}\right)$. Data given are the means for triplicate samples taken from two separate experiments.

\begin{tabular}{|c|c|c|c|c|c|c|}
\hline \multirow{2}{*}{$\begin{array}{l}\text { Initial no. } \\
\text { of cysts } \mathrm{ml}^{-1}\end{array}$} & \multicolumn{6}{|c|}{ Percentage excystment after } \\
\hline & $4 \mathrm{~h}$ & $8 \mathrm{~h}$ & I $2 \mathrm{~h}$ & $16 \mathrm{~h}$ & $20 \mathrm{~h}$ & $24 \mathrm{~h}$ \\
\hline $1 \times 10^{5}$ & 6 & 17 & 29 & 42 & 63 & $8 \mathbf{I}$ \\
\hline $5 \times 10^{5}$ & 4 & I I & $2 \mathrm{I}$ & 30 & 52 & 67 \\
\hline $1 \times 10^{6}$ & 3 & 7 & I 8 & 25 & 43 & $5 \mathrm{I}$ \\
\hline $5 \times 10^{6}$ & 3 & 7 & I 5 & 23 & 37 & 47 \\
\hline
\end{tabular}

trophozoites. Thus, there was a $12 \%$ increase in the total number of amoebae at $48 \mathrm{~h}$ but the number of empty cysts decreased due to degradation. The count of trophozoites and empty cysts at $24 \mathrm{~h}$ therefore gives a good indication of the degree of excystment. Since most of the excystment described here was done using only bacterial extract the counts of trophozoites at $48 \mathrm{~h}$ represent an accurate estimation of the degree of excystment. In growth medium at $48 \mathrm{~h}$, the multiplication of amoebae was likely to have vitiated the result of the count. However, the haemocytometer counts up to $24 \mathrm{~h}$ during which there was no multiplication of trophozoites, would represent the extent of excystment.

\section{Factors affecting the excystment of $H$. culbertsoni}

E. coli extract. This readily promotes the excystment of axenically prepared cysts of H. culbertsoni. The extract caused $50 \%$ excystment at a I : I 600 dilution and still gave 35 to $40 \%$ excystment at $\mathrm{I}: \mathrm{I} 2800$ dilution.

Cyst concentration. Excystment depended upon the concentration of cysts in the excystment medium (Table 2). There was extensive excystment within $24 \mathrm{~h}$ with $\mathrm{I} \times 10^{5} \mathrm{cysts}^{-1}$ but with $5 \times \mathrm{IO}^{6}$ cysts $\mathrm{ml}^{-1}$ only $47 \%$ of cysts had excysted. The rate of excystment was linear until it reached the maximum at about $24 \mathrm{~h}$.

Time of exposure of the cysts to E. coli extract. Cysts were incubated in E. coli extract for different periods and were then washed free of the extract. They were then incubated in $0.5 \%$ sterile $\mathrm{NaCl}$ and the degree of excystment measured at 24 and $48 \mathrm{~h}$ intervals. The results (Table 3 ) suggest that the factors have to be present throughout for bringing about excystment.

$\mathrm{HCl}$, sodium lauryl sulphate and trypsin. The effect of treatment with different concentrations of sodium lauryl sulphate and $\mathrm{HCl}$ on the excystment and viability of cysts as judged by eosin staining was studied. Low concentrations ( $0 . \mathrm{I}$ to I $\%$ ) of $\mathrm{HCl}$ and sodium lauryl sulphate did not affect the cysts up to $24 \mathrm{~h}$ exposure. However, treatment with $2 \% \mathrm{HCl}$ or 
Table 3. Effect of E. coli extract on excystment of $H$. culbertsoni

The cysts were pre-incubated for various periods in $E$. coli extract (Io $\mathrm{mg} \mathrm{ml}^{-1}$ ) and then transferred to $0.5 \% \mathrm{NaCl}$ and incubated for $48 \mathrm{~h}$. Data are the means of counts in a haemocytometer for triplicate samples taken from two separate experiments.

\begin{tabular}{|c|c|c|c|c|c|c|}
\hline \multirow{4}{*}{$\begin{array}{l}\text { Pre-incubation time } \\
\text { of cysts in the } \\
E \text {. coli extract (h) }\end{array}$} & \multicolumn{6}{|c|}{ Relative $\%$ of forms of organism after } \\
\hline & \multicolumn{3}{|c|}{$24 \mathrm{~h}$} & \multicolumn{3}{|c|}{$48 \mathrm{~h}$} \\
\hline & \multicolumn{3}{|c|}{ Intermediate } & \multicolumn{3}{|c|}{ Intermediate } \\
\hline & Cysts & form & Trophozoite & Cysts & form & Trophozoite \\
\hline 0 & 100 & 0 & o & 100 & 0 & o \\
\hline 4 & 49 & 45 & 5 & 49 & 45 & 6 \\
\hline 8 & 47 & 42 & II & 47 & 42 & I I \\
\hline 12 & 37 & 42 & $2 I$ & 37 & 42 & $2 \mathrm{I}$ \\
\hline 24 & 20 & I I & 69 & 20 & I I & 69 \\
\hline 48 & 10 & 14 & 76 & IO & 9 & $8 \mathrm{I}$ \\
\hline
\end{tabular}

$2 \%$ lauryl sulphate for $24 \mathrm{~h}$ adversely affected the viability of cysts. Treatment of cysts as such with trypsin (I \%, I00 mM-Tris buffer, $\mathrm{pH} 7.6)$ for Io min enhanced excystment. When $\mathrm{HCl}$-treated cysts were subjected to trypsin treatment, excystment was increased from 67 to $83 \%$.

Different bacterial and fungal extracts. Aqueous extracts of $B$. subtilis, B. megaterium, Sarcina lutea and $S$. aureus promoted 65 to $80 \%$ excystment after $24 \mathrm{~h}$ exposure and 85 to $90 \%$ after $48 \mathrm{~h}$ exposure. Extracts from A. niger, C. globosum, T. viride and $M$. verrucaria also promoted good excystment.

Growth medium and protein hydrolysate. The growth medium for $H$. culbertsoni gave good excystment. Peptone (I to $2 \%$ ) itself was also effective but adding thiamin and cyanocobalamin had no significant effect (Table 4 ). Other proteinaceous substrates, such as tryptone or proteose peptone, were equally effective in promoting excystment.

Amino acids. Different amino acids $\left(\mathrm{IO}^{-2}\right.$ to $\left.\mathrm{IO}^{-3} \mathrm{M}\right)$ caused varying degrees of excystment of axenically prepared cysts of $H$. culbertsoni (Table 5). Glutamic acid was the most potent followed by serine, threonine and alanine. Excystment was low with the basic and aromatic amino acids. No linear or quantitative relationship was observed between the concentrations of amino acids and the degree of excystment.

\section{DISCUSSION}

Factors causing excystment seem to be of wide and almost ubiquitous occurrence. Peptones and protein hydrolysates, and extracts from several Gram-positive and Gramnegative, sporulating and non-sporulating bacteria promoted this activity. Fungal extracts also promoted excystment. Since the growth of amoebae as well as encystment took place under sterile conditions and sterility was also maintained during excystment, the excystment activity of the media employed cannot be ascribed to bacterial contaminants. The excystation mediated by cell-free extracts of bacteria and fungi must be associated with some chemical entities present in them. That amino acids are among the important agents that cause excystment is to be inferred from their presence in cell-free extracts as well as in peptones. The earlier studies of Singh et al. (1958) and rigorous fractionation of $E$. coli extract (Kaushal, Shukla \& Krishna Murti, unpublished observation) suggest that the excystment promoting activity of cell-free bacterial extracts may indeed be due to the presence of amino acids. 


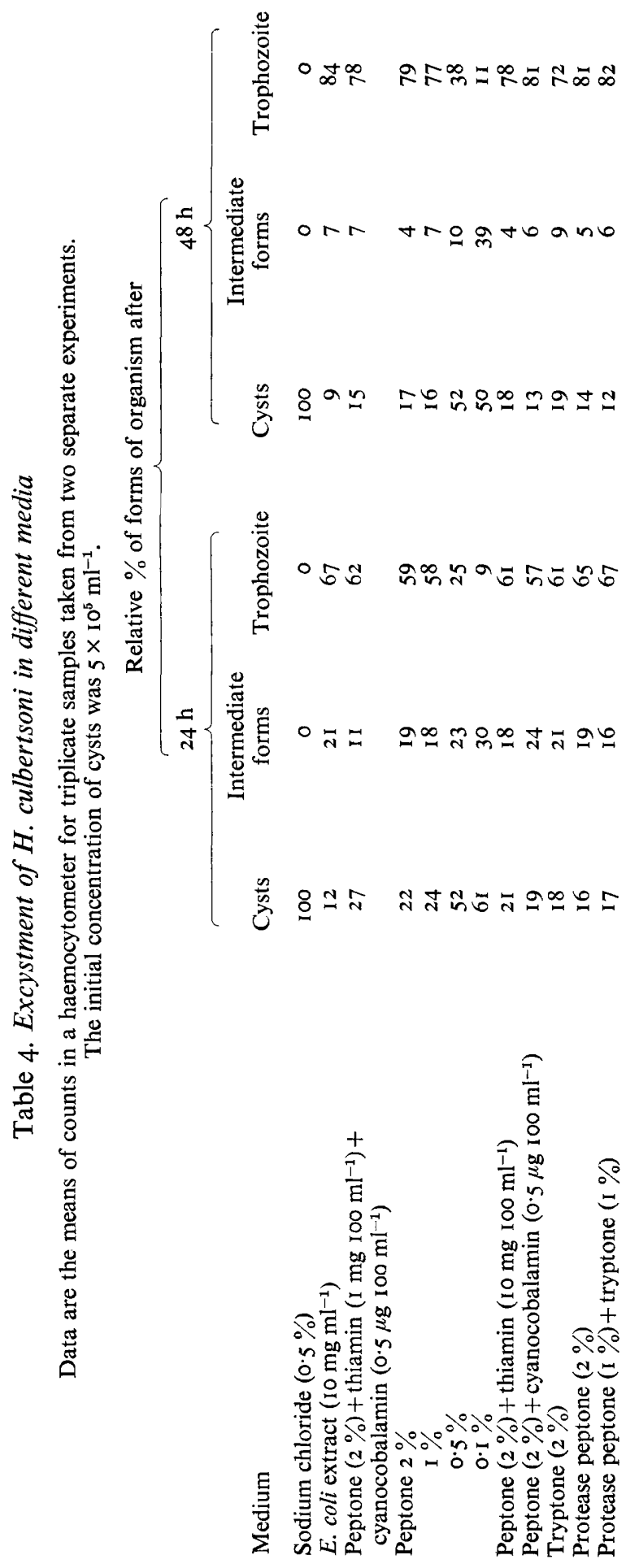




\section{Table 5. Effect of amino acids on excystment of $H$. culbertsoni}

Cysts at $5 \times 10^{5} \mathrm{ml}^{-1}$ were incubated for 24 h. E. coli extract $\left(10 \mathrm{mg} \mathrm{ml}^{-1}\right)$ as the standard gave $67 \%$ excystment; $\mathrm{NaCl}(0.5 \%)$ as the control gave none. The $\mathrm{pH}$ of the amino acid solutions was adjusted to $6 \cdot 5-7 \cdot 0$; similar results were obtained using the amino acids at $10^{-2} \mathrm{M}$. Data are the means of counts in a haemocytometer for triplicate samples taken from two separate experiments.

\begin{tabular}{|c|c|c|c|}
\hline Amino acids $\left(10^{-3} \mathrm{M}\right)$ & $\begin{array}{c}\text { Excystment } \\
(\%)\end{array}$ & Amino acids $\left(\mathrm{IO}^{-3} \mathrm{M}\right)$ & $\begin{array}{c}\text { Excystment } \\
(\%)\end{array}$ \\
\hline$\beta$-Alanine & 30 & L-Lysine & $2 I$ \\
\hline DL-Alanine & 29 & DL-Methionine & 12 \\
\hline L-Arginine. $\mathrm{HCl}$ & 2 & DL-Methionine & \\
\hline L-Asparagine & 21 & sulphoxide & $2 \mathrm{I}$ \\
\hline DL-Aspartic acid & 28 & DL-Norleucine & 7 \\
\hline L-Aspartic acid & 20 & DL-Norvaline & 27 \\
\hline L-Cysteic acid & 19 & DL-Ornithine. $\mathrm{HCl}$ & 13 \\
\hline L-Cysteine. $\mathrm{HCl}$ & 15 & L-Ornithine. $\mathrm{HCl}$ & 19 \\
\hline L-Cystine & $3 I$ & L-Phenylalanine & $2 I$ \\
\hline DL-Glutamic acid & 43 & L-Proline & 8 \\
\hline L-Glutamic acid & 39 & DL-Serine & 32 \\
\hline L-Glutamine & 28 & L-Serine & 31 \\
\hline Glycine & 23 & DL-Threonine & 32 \\
\hline L-Histidine. $\mathrm{HCl}$ & 13 & L-Threonine & 34 \\
\hline Hydroxy L-Proline & 23 & DL-Tryptophan & 13 \\
\hline Isoleucine & 14 & L-Tryptophan & I I \\
\hline DL-Leucine & I 8 & DL-Tyrosine & 14 \\
\hline L-Leucine & 8 & L-Tyrosine & I I \\
\hline DL-Lysine. $\mathrm{HCl}$ & 19 & DL-Valine & $3 \mathbf{I}$ \\
\hline
\end{tabular}

Treatment of cysts with $\mathrm{HCl}$ and trypsin accelerates excystment. This may be either due to increased permeability of cysts or to the unmasking of receptor sites for the excystment agents.

Excystment in the cysts of $H$. culbertsoni was noticed even with very low concentration of the factor although higher concentrations were required for quantitative excystment. No linear relationship was observed between the amount of excystation agent and the degree of excystment. Whether the induced excystment was preceded by uptake and binding of the factor responsible could not be discerned from the present studies. A high concentraion of cysts leading to crowding of the environment adversely affected excystment.

Continuous presence of excystment factor was essential and removal of the agent stopped further excystment. This may indicate the absence of a trigger mechanism in excystment. Alternatively, on the basis of the asynchronous nature of the cyst population, it may be that all cells do not respond to the triggering action of the agents simultaneously.

The authors would like to thank Dr C. R. Krishna Murti for his continuous encouragement and guidance throughout this work. D.C.K. would like to thank the Council of Scientific and Industrial Research for the award of a Senior Research Fellowship.

This is communication no. 2055 from Central Drug Research Institute, Lucknow 226001, India.

\section{REFERENCES}

BEERS, C. D. (1946). Excystment of Didinium nasutum, with special reference to the role of bacteria. Journal of Experimental Zoology ro3, $201-231$.

Crump, L. M. (1950). The influence of bacterial environment on the excystment of amoebae from soil. Journal of General Microbiology 4, 16-21.

Drozanski, W. (I96I). The influence of bacteria on the excystment of soil amoebae. Acta microbiologia folonica 10, I47-153. 
DudzIAK, B. (I955). The influence of the temperature and the bacterial environment on the excystment and growth of soil-amoebae. Acta microbiologia polonica 4, I I 5-125.

Hall, R. P. (1953). Protozoology. New York: Prentice-Hall, Inc.

Imam, S. A., DutTa, G. P. \& Agarwala, S. C. (1968). Inhibition of excystment of Schizopyrenus russelli cysts in the presence of emetine and its cyticidal effect in conjunction with sodium lauryl sulphate. Journal of General Microbiology 51, 17-22.

JefFries, W. B. (I962). Studies on specific chemicals as excysting agents for Pleurotricha lanceolata. Journal of Protozoology 9, 375-376.

Jehan, M., Dutta, G. P., Kaushal, D. C. \& Shukla, O. P. (1975). Effect of bacterial \& fungal extracts and metabolic inhibitors on excystment of soil amoebae. Indian Journal of Experimental Biology 13, 375-377.

Kaushal, D. C. \& Shukla, O. P. (1975). Simple medium for the growth of Hartmannella culbertsoni and its encystation. Indian Journal of Experimental Biology 13, 247-252.

Kaushal, D. C. \& Shukla, O. P. (1976). Release of certain extra-cellular enzymes during excystment of axenically produced cysts of Hartmannella culbertsoni. Indian Journal of Experimental Biology 14, 498-499.

SingH, B. N. (1973). Current status of the problems of exogenous and endogenous amoebiasis. Journal of Scientific and Industrial Research 32, 399-432.

SiNGH, B. N. \& DAS, S. R. (I970). Studies on pathogenic and non-pathogenic small free-living amoebae and the bearing of nuclear division on the classification of the order Amoebide. Philosophical Transactions of the Royal Society of London 259, 436-476.

Singh, B. N., MATHEw, S. \& ANAND, N. (1958). The role of Aerobacter sp., Escherichia coli and certain amino acids in the excystment of Schizopyrenus russelli. Journal of General Microbiology 19, 104-111.

Singh, B. N. Das, S. R. \& SaXena, U. (r963). A simple and reliable method for obtaining viable sterile cysts of Entamoeba histolytica from human faeces for monobacterial culture. Annals of Biochemistry and Experimental Medicine 23, 5I-56.

Singh, B. N., SAXena, U. \& Iyer, S. S. (I965). Preparation of viable sterile cysts of free-living amoebae and role of bacteria on excystment. Indian Journal of Experimental Biology 3, I $10-1$ I 2.

Singh, B. N., Mathew, S. \& Sreenivasaya, M. (1956). Occurrence and nature of amoebae excystment factor produced by Aerobacter sp. Nature, London 177, 62 I-622.

Singh, B. N., Datta, T. \& Dutta, G. P. (1971). Factors inducing excystation in free-living amoebae. Indian Journal of Experimental Biology 9, 350-367. 